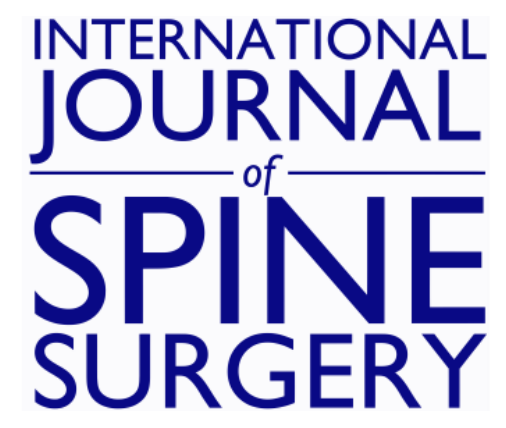

\title{
Inpatient versus Outpatient Anterior Cervical Discectomy and Fusion: A Perioperative Complication Analysis of 259,414 Patients From the Healthcare Cost and Utilization Project Databases
}

Shearwood McClelland, 3rd, Peter G Passias, Thomas J Errico, R Shay Bess and Themistocles S Protopsaltis

Int J Spine Surg 2017, 11 (2)

doi: https://doi.org/10.14444/4011

http://ijssurgery.com/content/11/2/11

This information is current as of April 25, 2023.

Email Alerts Receive free email-alerts when new articles cite this article. Sign up at:

http://ijssurgery.com/alerts

The International Journal of Sdpine Subrgerthttp://ijssurgery.com/ by guest on April 25, 2 2397 Waterbury Circle, Suite 1, 


\section{Inpatient versus Outpatient Anterior Cervical Discectomy and Fusion: A Perioperative Complication Analysis of 259,414 Patients From the Healthcare Cost and Utilization Project Databases}

Shearwood McClelland III MD, Peter G Passias MD, Thomas J Errico MD, R Shay Bess MD, Themistocles $S$ Protopsaltis MD

Division of Spine Surgery, Department of Orthopaedic Surgery, Hospital for Joint Diseases, NYU Langone Medical Center, New York, NY

\section{Abstract}

Background

Anterior cervical discectomy and fusion (ACDF) is one of the most common operations utilized to address pathology of the cervical spine. Few reports have attempted to compare complications associated with inpatient versus outpatient ACDF.

\section{Methods}

The Nationwide Inpatient Sample (NIS) from 2001-2012 and the State Ambulatory Services Database (SASD) for New Jersey (NJ) from 2003-2012 were used for analysis. Patients receiving ACDF (defined as anterior cervical fusion (ICD-0 code $=81.02)+$ excision of intervertebral disc (80.51)) were segmented into an inpatient group derived from the NIS, and an outpatient group derived from the NJ SASD. Patients receiving $>2$ levels fused (ICD-9 codes 81.63-81.64), or surgery for cancer (ICD-9 codes 140-239), or trauma (ICD-9 codes=805.0-806.9) were excluded. Propensity score matching (PSM) was used to adjust the analysis for patient age, race, sex, primary payer for care, and number of medical diagnoses.

Results

Of the 94,492,438 inpatients comprising the NIS from 2001-2012, 257,398 received ACDF. Of the 4,194,207 outpatients comprising the NJ SASD, 2,016 received ACDF. PSM of 10,080 patients (all 2,016 SASD and 8,064 from NIS) was performed, and subsequent analysis revealed that durotomy $(\mathrm{P}=0.001 ; \mathrm{OR}=0.81)$, paraplegia, postoperative infection, hematoma/seroma $(\mathrm{OR}=0.14)$, respiratory complications, acute posthemorrhagic anemia and red blood cell transfusion (all $\mathrm{P}<0.001)$ were less frequent in outpatient versus inpatient $\operatorname{ACDF}(\mathrm{p}<0.05)$. These results were similar to an unmatched analysis involving all of the NIS patients.

\section{Conclusion}

Accepting the limitations of the NIS and SASD (inability to distinguish between one and two-level fusions, no long-term follow-up, potential selection bias, disparities between inpatient and outpatient ACDF populations), these findings indicate that for 1-2 level ACDF, perioperative complications, including durotomy, paraplegia, hematoma, and acute posthemorrhagic anemia were more commonly reported following inpatient ACDF. Future studies involving outpatient analysis of several states will be necessary to determine whether these results of outpatient $\mathrm{ACDF}$ are applicable nationwide.

KEYWORDS: ANTERIOR CERVICAL DISCECTOMY AND FUSION, INPATIENT, OUTPATIENT, PERIOPERATIVE OUTCOMES, NATIONWIDE INPATIENT SAMPLE, STATE AMBULATORY AND SERVICES DATABASE

VOLUME 11 ISSUE 2 DOI: 10.14444/4011

PAGES $79-84$

\section{Introduction}

Anterior cervical discectomy and fusion (ACDF), first described by Smith, Robinson and Cloward in Downloaded from http://ijssurgery.com/ by guest on April 25, 2023

1958 is considered optimal treatment for a number of degenerative cervical spine conditions, and has markedly increased in volume over the past 20 years. ${ }^{1-3}$ Due to persistent and unsustainable growth 
in healthcare costs, with surgical care alone comprising $7 \%$ of the United States gross domestic product (GDP), cost-saving strategies such as outpatient and ambulatory surgery centers have increased in popularity, given that they cost approximately $30 \%$ less than comparable inpatient hospital procedures. ${ }^{4-5} \mathrm{Re}-$ cently, a few single-center studies using relatively small sample sizes have examined intraoperative and perioperative complications of outpatient ACDF in order to assess its safety, motivated in part by the realities of the current medical-legal climate..$^{6-7}$

The complications of outpatient versus inpatient ACDF have been examined sparsely in the literature, with only one study using a population-based database to examine surgical safety and quality between outpatient and inpatient ACDF. ${ }^{5,-9}$ The present study was performed to examine this area utilizing the Health Care Cost and Utilization Project (HCUP) databases, the largest family of populationbased databases cited in the peer-reviewed literature.

\section{Methods}

Data Source

This retrospective cohort study utilized the State Ambulatory Surgery and Services Database (SASD; overview available at https://www.hcup-us.ahrq.gov/ sasdoverview.jsp) for the state of New Jersey encompassing the years 2003 through 2012 and the Nationwide Inpatient Sample (2001-2012) which were obtained from HCUP, Agency for Healthcare Research and Quality (Rockville, MD). ${ }^{10-11}$ The SASD includes encounter-level data for ambulatory surgery and other outpatient services from hospital-owned facilities, with the specific types of ambulatory surgery and outpatient services varying by state and data year. The SASD from each state includes encounter-level outpatient data that are translated into a uniform format to facilitate multistate comparisons and analyses, and contains a core set of uniform clinical and nonclinical information on all patients, regardless of payer, including those covered by Medicare, Medicaid, private insurance, and the uninsured. Some SASD states include additional patient demographic information such as race. The NIS represents approximately $20 \%$ of all inpatient admissions to nonfederal hospitals in the United States (US). The NIS is com- prised of discharges from a stratified random sample of nonfederal hospitals in up to 45 states, approximating a $20 \%$ representative subsample of all US nonfederal hospital discharges.

\section{Inclusion and Exclusion Criteria}

Using the International Classification of Diseases, Ninth Revision, Clinical Modification diagnosis and treatment codes, discharges were identified for those patients undergoing ACDF (defined as anterior cervical fusion (ICD-0 code=81.02) + excision of intervertebral disc (80.51)). All ACDF patients were segmented into an inpatient group derived from the NIS, and an outpatient group derived from the NJ SASD. Patients with $>3$ vertebrae ( $>2$ levels) fused (ICD-9 codes 81.63-81.64), cancer (ICD-9 codes 140-239), or trauma (ICD-9 codes $=805.0-806.9$ ) were excluded. Additionally, any patient with any missing data for age, sex, total hospital cost, inhospital mortality, hospital length of stay, number of procedures (defined as number of procedures coded on the discharge record) and number of diagnoses (defined as total number of diagnoses coded on the discharge record) was excluded.

\section{Data Collection}

Demographic data for age, race, gender, median household income for postal (ZIP) code of residence, and primary payer (Medicare, Medicaid, private insurance, self-pay, no charge, or other), were analyzed in this study. A total of 14 postoperative complications were analyzed to assess the impact of outpatient versus inpatient ACDF on each variable (Table 2). These variables were selected based on previous work involving population-based databases to conduct postoperative analyses and known perioperative ACDF complications. ${ }^{5}$

\section{Statistical Analysis}

Statistical analysis was performed using SPSS version 17 (IBM Corporation, Armonk, New York). The characteristics of patients, providers and hospitals were summarized by descriptive statistics. Propensity score matching (PSM) was performed using $R$ 3.2.3 (R Foundation for Statistical Computing, Vienna, Austria) assisted by MatchIt, rgenoud, and Matching packages. ${ }^{12-15}$ PSM was performed separately on more than 8,000 inpatients and all outpa- 
tients receiving $\mathrm{ACDF}$ adjusting for age, race, sex, primary payer of care, and number of diagnoses. Following PSM, postoperative variables was analyzed using chi-square testing, with significance defined as a $P$ value less than 0.05 . Sample size calculations were performed using MapleTech online software (http://www.calculator.net/sample-sizecalculator.html).

\section{Results}

\section{Patient Demographics}

From 2001 through 2012, the NIS database contained $94,492,438$ patients, of whom 257,398 (0.3\%) received ACDF. Of the 4,194,207 outpatients comprising the 2003-2012 NJ SASD, 2,016 (0.05\%) received ACDF, for a total of 259,414 patients who received ACDF. The demographic distribution of patients in both cohorts by age, sex, race, number of diagnoses, insurance status, and primary payer is listed in Table 1, with one-way ANOVA testing used for analysis. The overall differences between the two cohorts represented a significant reason for PSM to be performed (Table 1).

Sample size calculations revealed that a minimum of 384 outpatients receiving ACDF would be needed to achieve a confidence level of $95 \%$ at a confidence interval of $5 \%$ for perioperative outcomes; consequently the sample size of 2,016 outpatient ACDF procedures ensured that this study was sufficiently powered.

Table 1. Unmatched demographic and operative data for inpatient and outpatient ACDF.

\begin{tabular}{|l|r|r|l|}
\hline & $\begin{array}{r}\text { Inpatient } \\
\text { ACDF } \\
(\mathbf{n = 2 5 7 , 3 9 8})\end{array}$ & $\begin{array}{r}\text { Outpatient } \\
\text { ACDF } \\
(\mathbf{n}=\mathbf{2 , 0 1 6})\end{array}$ & P value \\
\hline Age (years) & 51 & 47.7 & $<0.001$ \\
\hline Female sex & $52 \%$ & $47 \%$ & $<0.001$ \\
\hline Caucasian race & $63 \%$ & $75 \%$ & $<0.001$ \\
\hline Medicaid as Primary Payer & $0.06 \%$ & $0.01 \%$ & $<0.001$ \\
\hline $\begin{array}{l}\text { Hospital Length of Stay } \\
\text { (days) }\end{array}$ & 2.12 & 0.17 & $<0.001$ \\
\hline Number of Diagnoses & 4.61 & 2.90 & $<0.001$ \\
\hline $\begin{array}{l}\text { Number of Procedures Per- } \\
\text { formed }\end{array}$ & 3.85 & 3.96 & 0.001 \\
\hline
\end{tabular}

\section{Outpatient versus Inpatient ACDF}

Due to the volume of inpatients receiving ACDF, PSM was performed on a 10,080 patient subset, which included all 2,016 SASD outpatients and 8,064 randomly selected NIS inpatients. Following PSM, subsequent analysis found outpatient ACDF to be associated with decreased durotomy, paraplegia, postoperative infection, hematoma/seroma, respiratory complications, acute posthemorrhagic anemia, and red blood cell transfusion (Table 2; all $\mathrm{P} \leq$ 0.001). Odds ratios were calculable for durotomy and hematoma/seroma, and were 0.81 and 0.14 respectively for outpatient versus inpatient ACDF.

\section{Discussion}

There has been recent increased interest in pursuing outpatient ACDF, due to the cost-savings that outpa-

\begin{tabular}{|c|c|c|c|c|}
\hline $\begin{array}{l}\text { Postoperative } \\
\text { Complication }\end{array}$ & $\begin{array}{r}\text { Inpatient } \\
\text { ACDF }\end{array}$ & $\begin{array}{r}\text { Outpatient } \\
\text { ACDF }\end{array}$ & $P$ value & $\begin{array}{l}\text { Odds } \\
\text { Ratio }\end{array}$ \\
\hline Durotomy & $49 / 8,015$ & $1 / 2,015$ & 0.001 & 0.81 \\
\hline Arm Paralysis & $7 / 8,057$ & $0 / 2,016$ & 0.358 & N/A \\
\hline Leg Paralysis & $4 / 8,060$ & $0 / 2,016$ & 0.590 & N/A \\
\hline Paraplegia & $60 / 8,004$ & $0 / 2,016$ & $<0.001$ & N/A \\
\hline Postoperative Infection & $75 / 7,989$ & $0 / 2,016$ & $<0.001$ & N/A \\
\hline Hematoma/Seroma & $273 / 7,791$ & $1 / 2,015$ & $<0.001$ & 0.14 \\
\hline $\begin{array}{l}\text { Foreign Body } \\
\text { Retainment }\end{array}$ & $2 / 8,062$ & $0 / 2,016$ & 1.000 & $\mathrm{~N} / \mathrm{A}$ \\
\hline $\begin{array}{l}\text { Acute Reaction to } \\
\text { Foreign Body }\end{array}$ & $0 / 8,064$ & $0 / 2,016$ & N/A & N/A \\
\hline $\begin{array}{l}\text { Rh-Incompatible } \\
\text { Reaction }\end{array}$ & $0 / 8,064$ & $0 / 2,016$ & N/A & N/A \\
\hline $\begin{array}{l}\text { Other Transfusion } \\
\text { Reaction }\end{array}$ & $2 / 8,062$ & $0 / 2,016$ & 1.000 & N/A \\
\hline $\begin{array}{l}\text { Respiratory } \\
\text { Complications }\end{array}$ & $221 / 7,843$ & $0 / 2,016$ & $<0.001$ & N/A \\
\hline $\begin{array}{l}\text { Acute Posthemorrhagic } \\
\text { Anemia }\end{array}$ & $447 / 7,617$ & $0 / 2,016$ & $<0.001$ & N/A \\
\hline Dysphonia & $15 / 8,049$ & $0 / 2,016$ & 0.053 & N/A \\
\hline $\begin{array}{l}\text { Red Blood Cell } \\
\text { Transfusion }\end{array}$ & $290 / 7,774$ & $0 / 2,016$ & $<0.001$ & N/A \\
\hline
\end{tabular}

Downloaded from http://ijssurgery.com/ by guest on April 25, 2023 
tient procedures have compared with their inpatient counterparts. ${ }^{4}$ However, such savings is only beneficial if outpatient ACDF is shown to be comparably safe and efficacious as traditional inpatient ACDF. The goal of this study was to further investigate this issue, using sample sizes far greater than any previously reported in the literature. ${ }^{5,-9}$ The $259,414 \mathrm{pa}$ tients examined in this study is more than 35 times greater than the previous largest study comparing inpatient versus outpatient ACDF, which involved fewer than 7,300 patients. $^{5}$

Our results indicate that in the perioperative period for fusions of 1-2 levels, outpatient ACDF was associated with fewer perioperative complications than inpatient $\mathrm{ACDF}$, most prominently with regard to paraplegia, postoperative infection, respiratory complications, acute posthemorrhagic anemia, and red blood cell transfusion requirement. Intriguingly, ACDF performed on an outpatient basis was 19\% less likely to result in an intraoperative durotomy, and $86 \%$ less likely to result in a postoperative hematoma or seroma. These findings may be due to potential reporting bias between inpatient and outpatient centers, since hospitals (unlike ambulatory centers) are incentivized to report comorbidities and complications. Another potential explanation may be the significantly greater proportion of Medicaid patients in the inpatient group (Table 1), since Medicaid patients are more likely to have medical problems, associated comorbidities, and require longer hospitalization. ${ }^{16}$ The fact that the inpatient group also had significantly more diagnoses than the outpatient group may also have played a role in our findings (Table 1). Consistent with multiple peer-reviewed publications using HCUP databases spanning several medical disciplines, this study provides level $2 \mathrm{~b}$ evidence. ${ }^{17-18}$

\section{Limitations}

There are several limitations of this study, the most prominent being its retrospective nature and reliance on a single state for outpatient data. The reliance on the NIS and SASD allows for potential uncertainty regarding the accuracy of case assignment for the database - it is theoretically possible that coding decisions between the hospitals involved were made by personnel with limited clinical experience and may have been influenced by nonclinical factors, such as reimbursement. This reliance on coding also prohibits the differentiation between one-level and twolevel fusions (respectively two vertebrae and three vertebrae fusions), since they both share the same ICD-9 procedure code of 81.62 ; this code also prohibits differentiating primary versus revision fusions. Another limitation is that while the number of diagnoses is recorded in both NIS and SASD, the relative severity of these was not accessible for this study. Furthermore, neither the NIS nor SASD allows for determination of the chronological relation between the ICD-9 codes and the surgical procedure, which eliminates the possibility of performing analysis involving temporal association. A further limitation is that neither database allows for elucidation as to the criteria for patient selection; therefore it is possible that the results from this study are due to selection bias between patients deemed appropriate for inpatient but not outpatient ACDF, potentially due to technical difficulty or case complexity. This criticism is strengthened by the fact that the inpatient group had significantly more medical comorbidities diagnosed than the outpatient group (Table 1). However, it is also possible that patients who would have been deemed by the surgeon to be suitable for outpatient surgery may not have been able to receive it due to insurance or hospital staffing concerns. Finally, because neither the NIS nor SASD allows for capture of data upon readmission, it is unable to provide postsurgical data beyond the time the patients were initially discharged. Unfortunately, any subsequent complications would not have been captured by the NIS or SASD, even if they occurred within the first 30 days postoperatively. Therefore the results from this study must be interpreted strictly on a perioperative basis, which weakens the applicability of these findings given the lack of follow-up.

\section{Conclusions}

Accepting the limitations of the NIS and SASD, these findings comprising a 12 -year nationwide inpatient analysis and a 10-year single-state outpatient analysis of more than 250,000 total patients indicate that outpatient $\mathrm{ACDF}$ may yield fewer perioperative complications than inpatient ACDF, including durotomy, hematoma, paraplegia, respiratory complications, and anemia. These findings (level $2 \mathrm{~b}$ evi- 
dence), comprising by far the largest sample size in the published literature, indicate that for ACDFs of 1-2 levels, outpatient ACDF may not be inferior to inpatient $\mathrm{ACDF}$ on a perioperative basis. Further studies involving longer-term follow-up will be necessary to determine if these findings persist over time.

\section{References}

1. Cloward RB. The anterior approach for removal of ruptured cervical disks. J Neurosurg 15:602-617, 1958.

2. Smith GW, Robinson RA. The treatment of certain cervical spine disorders by anterior removal of the intervertebral disc and interbody fusion. J Bone Joint Surg Am 40-A:607-624, 1958.

3. Marawar S, Girardi FP, Sama AA, Ma Y, GaberBaylis LK, Besculides MC, Memtsoudis SG. National trends in anterior cervical fusion procedures. Spine (Phila Pa 1976) 35:1454-1459, 2010.

4. Wang MC, Kreuter W, Wolfla CE, Maiman DJ, Deyo RA. Trends and variations in cervical spine surgery in the United States: Medicare beneficiaries, 1992 to 2005. Spine (Phila Pa 1976) 34:955-963, 2009.

5. McGirt MJ, Godil SS, Asher AL, Parker SL, Devin CJ. Quality analysis of anterior cervical discectomy and fusion in the outpatient versus inpatient setting: analysis of 7288 patients from the NSQIP database. Neurosurg Focus. 2015 Dec;39(6):E9 6. Villavicencio AT, Pushchak E, Burneikiene $S$, Thramann JJ. The safety of instrumented outpatient anterior cervical discectomy and fusion. Spine J. 2007 Mar-Apr;7(2):148-53.

7. Tally WC, Tarabadkar S, Kovalenko BV. Safety and feasibility of outpatient ACDF in an ambulatory setting: A retrospective chart review. Int J Spine Surg. 2013 Dec 1;7:e84-7.

8. Liu JT, Briner RP, Friedman JA. Comparison of inpatient versus outpatient anterior cervical discectomy and fusion: a retrospective case series. BMC Surg 9:3, 2009.

9. Adamson T, Godil SS, Mehrlich M, Mendenhall S, Asher AL, McGirt MJ. Anterior cervical discectomy and fusion in the outpatient ambulatory surgery setting compared with the inpatient hospital setting: analysis of 1000 consecutive cases. J Neurosurg Spine. 2016 Feb 5:1-7.

10. Healthcare Cost and Utilization Project

(HCUP): 2010 Introduction to the Nationwide Inpatient Sample (NIS). Agency for Healthcare Research and Quality January 2013; http://www.hcupus.ahrq.gov/db/nation/nis/

NIS_Introduction_2010.jsp. Accessed February 20, 2014.

11. Healthcare Cost and Utilization Project

(HCUP): 2014 Introduction to the HCUP State Ambulatory Surgery and Services Database (SASD).

Agency for Healthcare Research and Quality August 2014; http://www.hcup-us.ahrq.gov/db/state/sasddist/Introduction_to_SASD.pdf. Accessed July 30, 2015.

12. R Developmental Core Team. R: A language and environment for statistical computing. Retrieved from http://ww.R-project.org. Accessed January 14, 2016.

13. Ho DE, Imai K, King G, Stuart EA. MatchIt: Nonparametric Preprocessing for Parametric Causal Inference. J Stat Softw. 2011;42(8):1-28.

14. Mebane W Jr, Sekhon JS. Genetic Optimization Using Derivatives: The rgenoud package for R. J Stat Softw. 2011;42(11):1-26

15. Sekhon JS. Multivariate and Propensity Score Matching Software with Automated Balance Optimization: The Matching package for R. J Stat Softw. 2011;42(7):1-52.

16. Waits SA, Reames BN, Sheetz KH, Englesbe MJ, Campbell DA Jr. Anticipating the effects of Medicaid expansion on surgical care. JAMA Surg. 2014;149(7):745-747.

17. Stroup SP, Palazzi KL, Chang DC, Ward NT, Parsons JK. Inpatient safety trends in laparoscopic and open nephrectomy for renal tumours. BJU Int. 2012;110(11):1808-13.

18. McClelland S 3rd, Ukwuoma OI, Lunos S, Okuyemi KS. The natural history of Dandy-Walker syndrome in the United States: A population-based analysis. J Neurosci Rural Pract. 2015;6(1):23-6.

\section{Disclosures \& COI}

All authors report no relevant financial disclosures. 


\section{Corresponding Author}

Shearwood McClelland III, M.D., Spine Research Institute, NYU Hospital for Joint Diseases, Department of Orthopaedic Surgery, 306 East 15th Street, Ground Floor, New York, NY 10003. drwood@post.harvard.edu.
Published 3 April 2017.

This manuscript is generously published free of charge by ISASS, the International Society for the Advancement of Spine Surgery. Copyright ๑ 2017 ISASS. To see more or order reprints or permissions, see http://ijssurgery.com. 